\title{
The Treatment of Obesity in Cardiac Rehabilitation
}

\author{
Philip A. Ades, MD ${ }^{1}$, Patrick D. Savage, $\mathbf{M S}^{1}$, and Jean Harvey-Berino, PhD, RD² \\ ${ }^{1}$ Division of Cardiology, University of Vermont College of Medicine, Burlington, VT \\ ${ }^{2}$ Nutrition and Food Sciences, University of Vermont College of Medicine, Burlington, VT
}

\begin{abstract}
Obesity is an independent risk factor for the development of coronary heart disease (CHD). At entry into cardiac rehabilitation (CR) over $80 \%$ of patients are overweight and over $50 \%$ have the metabolic syndrome. Yet, CR programs do not generally include weight loss programs as a programmatic component and weight loss outcomes in CR have been abysmal. A recently published study outlines a template for weight reduction based upon a combination of behavioral weight loss counseling and an approach to exercise that maximized exercise-related caloric expenditure. This approach to exercise optimally includes walking as the primary exercise modality and eventually requires almost daily longer distance exercise to maximize caloric expenditure. Additionally, lifestyle exercise such as stair climbing and avoidance of energy-saving devices should be incorporated into the daily routine. Risk factor benefits of weight loss and exercise training in overweight patients with coronary heart disease are broad and compelling. Improvements in insulin resistance, lipid profiles, blood pressure, clotting abnormalities, endothelial-dependent vasodilatory capacity, and measures of inflammation such as $\mathrm{C}$-reactive protein have all been demonstrated. $\mathrm{CR} /$ secondary prevention programs can no longer ignore the challenge of obesity management in patients with CHD. Individual programs need to develop clinically effective and culturally sensitive approaches to weight control. Finally, multicenter randomized clinical trials of weight loss in CHD patients with assessment of long-term clinical outcomes need to be performed.
\end{abstract}

\section{Key words or phrases}

Cardiac rehabilitation; Obesity; Weight loss; Exercise

\begin{abstract}
The prevalence of obesity has reached epidemic levels in industrialized societies. Since obesity is an independent risk factor for the development of coronary heart disease (CHD) its prevalence, like that of other cardiac disease risk factors, is amplified in CHD populations. In the United States, for example, the prevalence of overweight and obesity are at $66 \%$ and $32 \%$ respectively in the general population. In patients with CHD the corresponding prevalences are greater, at $80 \%$ and $40 \%$ respectively. ${ }^{1-4}$ From 1996 to 2006, the mean body mass index (BMI) of patients entering cardiac rehabilitation (CR) programs has increased from 28.5 to $30.1 \mathrm{~kg} / \mathrm{m}^{2} .{ }^{4}$ The prevalence of obesity $\left(\mathrm{BMI}>30 \mathrm{~kg} / \mathrm{m}^{2}\right.$ ) has increased by a remarkable $33 \%$ over this same time period. Despite the fact that weight reduction has been demonstrated to favorably affect multiple cardiac disease factors, ${ }^{5}$ weight loss programs are not regularly provided to patients in CR/Secondary Prevention programs.
\end{abstract}

The metabolic syndrome, also termed insulin resistance, is a collection of measurable markers of cardiac disease risk related to the presence of abdominal obesity and consequent insulin

Correspondence: Philip A. Ades MD, Director of Cardiac Rehabilitation and Preventive Cardiology, Fletcher-Allen Health Care, Professor of Medicine, University of Vermont College of Medicine, 62 Tilley Dr. S., Burlington, VT 05482, philip.ades@ vtmednet.org. 
resistance. ${ }^{6}$ According to the National Cholesterol Education Program, ${ }^{7,8}$ the presence of any 3 of the following 5 characteristics constitute the metabolic syndrome; waist circumference $>102 \mathrm{~cm}$ (men) and $>88 \mathrm{~cm}$ (women), systolic blood pressure $\geq 135 \mathrm{~mm} \mathrm{Hg}$ or diastolic blood pressure $\geq 85 \mathrm{~mm} \mathrm{Hg}$, fasting triglycerides $>150 \mathrm{mg} / \mathrm{dL}$, high density lipoprotein (HDL)cholesterol $<40 \mathrm{mg} / \mathrm{dL}$ (men) and $<50 \mathrm{mg} / \mathrm{dL}$ (women), and fasting blood glucose $>100 \mathrm{mg}$ / dL. Obesity and the metabolic syndrome predict an increased risk of death and recurrent events after myocardial infarction. ${ }^{9-14}$ Cardiac rehabilitation exercise and counseling, associated with even modest weight loss, significantly lowers the prevalence of metabolic syndrome in patients diagnosed prior to $\mathrm{CR}$ participation. ${ }^{15,16}$

We have recently demonstrated that more substantial weight loss in coronary patients (4-8 kg), accomplished by a combination of exercise and hypocaloric diet, is associated with more marked improvements in abdominal obesity, insulin resistance, lipid profiles, blood pressure, the components of metabolic syndrome, and clotting parameters than is seen in standard CR. 17 Thus, exercise and weight loss have the potential to favorably alter long-term clinical outcomes in overweight patients with CHD. We also note that lifestyle interventions, including exercise and weight loss, prevent the onset of type II diabetes mellitus with its attendant multiorgan system dysfunction, medications, and glucose testing. ${ }^{18}$ The prevention of Type 2 diabetes is a desirable goal as it is associated with poorer clinical outcomes in patients with established CHD. ${ }^{19-22}$

Intentional weight loss reduces the incidence of new cases of $\mathrm{CHD}^{23}$ in otherwise healthy individuals, and purposeful weight loss in the CR setting is associated with a reduced rate of composite cardiac events. ${ }^{24}$ However, in the clinical setting, effects of CR participation on weight loss for overweight and obese CHD patients have been modest at best (Table 1). ${ }^{3,15}$, ${ }^{25}$ Since an overall goal of comprehensive CR is to favorably alter lifestyle-related markers of cardiovascular disease risk, structured programs to yield meaningful and long-lasting weight reduction need to be developed for use. In this review, we propose a template for such a program.

\section{THE ENERGY BALANCE -WEIGHT LOSS EQUATION}

In free living adults, body weight is determined by the balance between energy intake (caloric content of food) and total energy expenditure (Figure 1). Total energy expenditure is partitioned into 3 components; the resting metabolic rate is the largest component (60-75\% of total); the thermic effect of food which is the energy required to digest food (generally $\pm 10 \%$ of total) is the second component; and physical activity energy expenditure, the most variable of the three components and largely under voluntary control, is the third (15-30\% of total). ${ }^{26}$ To accomplish weight loss, a net caloric deficit of 3500 calories equates to a weight loss of $1 / 2 \mathrm{~kg}$ (1 pound) of body weight. In reality one does not lose fat alone and weight reduction is also associated with loss of muscle which can be minimized by the concurrent performance of resistance training. ${ }^{27}$ In the clinical setting, energy intake can be reduced and energy expenditure can be increased using behavior modification principles.

\section{EXERCISE-MEDIATED WEIGHT LOSS IN CR}

Optimally, overweight patients with CHD entering CR should participate in a focused behavioral weight loss program that will shape their diet and exercise patterns. The exercise program prescribed should be one that maximizes caloric expenditure. However, we have observed that while essentially all new CR patients have agreed to undertake an exercise program and are thus in the "action-phase" regarding exercise, only a minority are in the action phase regarding their need to reduce dietary intake of calories. Motivating CR participants to undertake behavioral weight loss can be addressed on a case by case basis, preferentially with motivational interviewing. ${ }^{28}$ 
Mertens et $\mathrm{al}^{29}$ introduced the concept of exercise-alone as a means to attain long-term fat loss in overweight cardiac patients in a 1-year study of longer distance, almost daily, home-based walking. Patients were instructed to walk daily and over 3 months increased the duration of exercise until they attained 45 minutes per day. While there was no dietary caloric restriction, over a 1-year period subjects lost a mean of $4.5 \mathrm{~kg}$ of weight which was associated with favorable risk factor change. It is notable that these patients did not spontaneously increase their caloric intake to match the increase in exercise-related caloric expenditure thus, over time, weight loss was accomplished. While this study does not deny a potentially important role of dietary caloric restriction it introduces the concept that weight loss can be accomplished by a focused exercise program that maximizes caloric expenditure while maintaining caloric intake steady.

We built upon this concept in a study published in 2009 that randomized 74 overweight patients with CHD into either of 2 exercise programs with all patients provided a behavioral weight loss program. ${ }^{17}$ Half were randomized to an exercise program that maximized exercise-related energy expenditure with a goal of exceeding $3,000 \mathrm{kcal} /$ week whereas half were randomized to a standard CR exercise regimen that we and others have shown to expend approximately $700-800 \mathrm{kcal} /$ week. $^{30,31}$ To maximize exercise-related energy expenditure the exercise of choice was walking (or jogging) rather than weight supported exercise on cycle, arm or rowing ergometers which burns fewer calories ${ }^{32}$. Additionally, exercise was of longer duration and almost daily.

Study outcomes measured at 5 months included body weight, fat and lean mass measured by dual x-ray absorptiometery, waist circumference, and intra-abdominal fat total abdominal fat assessed by computed tomography scanning. We also measured markers of cardiovascular disease risk including a measure of insulin sensitivity using the euglycemic-hyperinsulinemic glucose clamp. This technique measures sensitivity to a defined postprandial concentration of insulin by determining the amount of infused glucose needed to maintain a steady glucose level. ${ }^{33}$ An insulin sensitive individual requires a high amount of infused glucose to maintain normoglycemia. An individual who is "resistant" to insulin action requires only a small amount of infused glucose to maintain steady state. We also measured other cardiac disease risk predictors that are related to obesity measures including lipid profiles, blood pressure, serum glucose, insulin levels, high-sensitivity C-reactive protein, plasminogen activator-inhibitor-1, flow-mediated vasodilator capacity, and platelet reactivity. Outcome measures were measured primarily after 5 months of the study interventions (including 1 month of weight stabilization) with selected measures also taken at 1 year.

At baseline, the study population was characterized by a mean age of 64 years, 60 males and 14 females, mean body weight was $94.7 \mathrm{~kg}$ ( $208 \mathrm{lbs}$ ), mean BMI=32, and mean waist circumference $=110 \mathrm{~cm}$, confirming substantial abdominal obesity (Table 2). Subjects were taking an array of preventive medications with $99 \%$ taking aspirin, $84 \%$ taking statins, and $72 \%$ taking beta-blockers; thus, baseline risk factors were relatively well controlled (Table 2). Baseline measures for insulin stimulated glucose disposal were low, documenting substantial insulin resistance. Patients with diabetes were excluded from the study as determined by an A.M. fasting glucose of $>126 \mathrm{mg} / \mathrm{dL}$ or the use of a glucose lowering medication.

Subjects in both study groups were enrolled in an identical behavioral weight loss program which met weekly for 16 weeks, then monthly until one year. Both groups reduced caloric intake similarly which at 15 weeks was reduced by $312 \pm 532 \mathrm{kcal} /$ day in the high-caloric exercise group and by $254 \pm 424 \mathrm{kcal} /$ day in the standard CR group $(P<0.05$ within groups, NS between groups measured by 24 hour dietary diaries). Characteristics of the behavioral weight loss intervention are described in greater detail below. 


\section{High-Caloric Expenditure Training in CR}

In our randomized-trial the high-caloric exercise group accomplished twice the weight loss and fat mass loss, and a greater reduction in waist circumference and CT scan measures of abdominal obesity than the standard CR group (Table 2). The increase in the amount of physical activity performed from week 1 to week 15 was the best correlate of the amount of weight loss (Figure 2, Figure 3). The high-caloric expenditure group also experienced a significantly greater increase in insulin-mediated glucose disposal reflecting a decrease in insulin resistance, the hallmark of the insulin resistance/metabolic syndrome. Additionally, the increased weight loss was associated with a greater decrease in the cholesterol/HDL-cholesterol ratio and a more favorable effect on a panel of risk factors than was seen in the standard CR group. The risk panel included a combined risk measure of insulin sensitivity, waist circumference, systolic and diastolic blood pressure, glucose, lipid measures, peak oxygen uptake $\left(\mathrm{VO}_{2}\right)$, C-reactive protein, and plasminogen-activator-inhibitor-1, statistically modeled with a multivariate analysis of variance. The high-caloric exercise group also experienced a greater reduction in the number of components of the metabolic syndrome compared with patients in the standard CR group: 3.1 to 1.9 components vs 2.4 to 2.0 components $(P<.05)$. The prevalence of metabolic syndrome was reduced from $59 \%$ to $31 \%$ in the combined study groups associated with a mean weight reduction of $6.2 \mathrm{~kg}$. Finally, brachial artery flow mediated dilatation was increased, and platelet reactivity was decreased to a greater degree in the high-caloric exercise groups. ${ }^{34,35}$

We note that our results were obtained in the setting of a hypocaloric diet and similar weight loss and risk factor reductions would be unlikely to occur with just high-caloric expenditure exercise alone. We also note that while each group regained approximately $1 \mathrm{~kg}$ from month 5 to month 12 , most of the weight loss was maintained and risk parameters remained improved at 12 months (Figure 4). ${ }^{17}$ Finally, there was no difference between groups in terms of change in peak $\mathrm{VO}_{2}$ at month 5 or month 12 when expressed in $\mathrm{L} / \mathrm{min}$.

\section{Implementing High-Caloric Expenditure Exercise in the CR Setting}

Ideally, individuals with CHD need to perform a symptom limited exercise tolerance test prior to embarking on an exercise training program. We have found that a minimal amount of fitness is required in order to perform an adequate amount of exercise to achieve a significant caloric expenditure. ${ }^{36}$ A fitness "threshold" of a peak aerobic capacity of roughly 14 $\mathrm{mL} \cdot \mathrm{kg}^{-1} \cdot \mathrm{min}^{-1}$ (4 metabolic equivalents) is needed to satisfactorily perform this type of training. While this level of fitness is quite low for otherwise healthy individuals, it is higher than many individuals entering CR. ${ }^{2}$ For very deconditioned individuals, the primary focus, initially, should be on improving fitness and when an adequate aerobic capacity is attained, the exercise prescription then could then be expanded to promote caloric expenditure (Table 3).

The over arching goal of high-caloric exercise is to maximize exercise related caloric energy expenditure. Especially for obese individuals, weight loss should be view as a long-term proposition with establishment of achievable, short term goals. Progress towards these goals should be reviewed frequently. As with all exercise prescriptions, there are 4 components that need to be considered: intensity, frequency, modality, and duration.

Intensity-Initially, exercise intensity should be light to moderate which, for most individuals, equates to approximately 60 to $70 \%$ of peak heart rate, measured on medications. In that overweight patients with CHD have a high prevalence of comorbid conditions, eg, arthritis and peripheral arterial disease, this can make exercise difficult to accomplish and may diminish long term adherence. Exercise performed at a lower intensity, as recommended for weight loss, may be more palatable and may help with avoidance of orthopedic related injuries. Lower intensity exercise also permits for longer duration sessions thus increasing caloric 
expenditure. Additionally, an exercise intensity of 60 to $70 \%$ of peak heart rate has been shown to be an adequate stimulus to improve cardiovascular fitness. ${ }^{37}$ Importantly, it is also an intensity that is well tolerated and, after a period of adequate supervision, can be performed safely away from the CR setting. ${ }^{38}$

As overweight patients with CHD lose weight and increase their exercise capacity, adjustment to intensity can be considered. For a given amount of time, an increase in exercise intensity will permit additional caloric expenditure. One needs to consider, however, the potential negative consequences of an increase in exercise intensity. There is a need to balance efficiency, ie, caloric expenditure per unit time, with a greater risk of injury or excessive fatigue that might come with exercise performed at a relatively higher intensity.

Frequency-When starting an exercise program an every other day schedule will allow for improvement in cardiovascular fitness while providing adequate recovery time. After an initial period of 1 to 3 weeks, the frequency of training should be increased to 5-7 days per week. Eventually, exercise therapy should be viewed as a medicine that is "dosed" nearly every day. Exercise performed nearly daily accomplishes 2 goals. First, increasing exercise frequency maximizes caloric expenditure. Secondly, it solidifies the exercise routine as a habit. Traditionally, CR programs have followed a 3 times per week training format with no clear recommendation for home exercise. As a result, patients experience more rest days than exercise days with a low weekly physical activity energy expenditure. ${ }^{30,31}$

For CR participants, daily exercise will necessitate that much of their exercise is done away from the rehabilitation facility. Additionally, the prolonged time requirements and associated equipment utilization makes high-caloric exercise problematic for CR programs with limited resources (both staff and exercise equipment). Establishing an exercise regimen that is at least in part, removed from the CR facility is a short-term imperative but may also help with longterm adherence as the patient will have established a long-term strategy for maintaining an exercise program prior to completing CR. ${ }^{39}$

Modality-The greatest exercise-related caloric expenditure occurs when the activity performed is not weight supported and large muscle groups are used. For example, a person will generally expend a greater number of calories with walking than they will with an arm or leg ergometry in a seated position for a similar duration of time. Another consideration regarding exercise that uses predominantly small muscles is that such activity will lead to earlier fatigue than activities involving large or multiple muscle groups. Other examples of high caloric expenditure activities are jogging, cross country skiing, elliptical trainers, dual-action cycle ergometers, and stair climbing. It may be advisable, however, to consider utilizing multiple modalities when first starting a training program. Using a variety of equipment will permit a greater exercise session duration than could be achieved if only a single mode of exercise is employed and overuse injuries may be avoided. As exercise tolerance improves, high caloric activities should be substituted for exercise that yields lower caloric expenditures. Inclement weather and/or injuries may necessitate the need to consider alternative training modalities. Additional caloric expenditure can be achieved by increasing activity levels separate from a defined exercise session. So-called "lifestyle activities" can result in significant caloric expenditure. To enhance daily caloric expenditure, an exercise counselor may provide guidance regarding the avoidance of energy saving devices; taking stairs instead of elevators; and utilizing walking, biking or public transport as alternative modes of transportation.

Duration-Initial exercise duration will depend on baseline fitness and activity level. When a sedentary individual is starting an exercise program, total duration may be relatively brief (20 to 30 minutes). As with all the components of the exercise prescription, duration should not be viewed in isolation. The goal of high-caloric expenditure exercise is to maximize weekly 
total energy expenditure, targeting $>3,000 \mathrm{kcal} /$ week if possible. Along with promoting weight loss, this level of weekly caloric expenditure has also been shown to halt the progression of angiographically measured coronary artery disease.$^{40}$ More unfit individuals or exercise performed less frequently than nearly everyday will require exercise sessions of longer duration. For most patients, 45 minutes to 1 hour will be required to achieve a satisfactory caloric expenditure if exercise is done 5-7 days per week and at a moderate intensity. When first starting an exercise program, shorter sessions should be performed to avoid overwhelming an historically sedentary individual with CHD. Patients should received reinforcement that while any exercise is good, more is better.

\section{PROGRAM COMPONENTS OF WEIGHT LOSS}

There are 3 standard components of any behavioral weight control program: behavior modification, diet, and exercise. ${ }^{41-44}$ These are discussed here along with expected outcomes and recommendations for program design and implementation.

\section{Behavior Modification}

Behavior modification principles focus on changing environmental factors that control behavior, specifically the antecedents or cues in the environment that set the stage for behavior and the consequences or reinforcers that follow behavior and lead to its recurrence. Common program components for weight reduction include self-monitoring, stimulus control, problem solving, goal setting, social support, relapse prevention, and positive reinforcement and feedback (Table 4). In the CR setting, the ultimate goal of a behavioral weight loss program is to produce lifelong changes in dietary and exercise behaviors resulting in permanent weight loss. Whereas CR programs generally provide for 12 or fewer weeks of clinical contact, weight loss - lifestyle modification programs are typically provided on a weekly basis for a longer period of time such as 16-24 weeks. Thus, in the CR setting, programs and individuals truly interested in longer-term weight reduction should plan for a more extended contact.

Treatment sessions are provided to groups of 10-20 individuals for approximately 60 minutes by a trained facilitator (registered dietitian, behavioral psychologist, nurse, exercise specialist, or related health-care professional). Group therapy appears to be more effective than individual treatment. Treatment visits are conducted using a structured curriculum. ${ }^{41}$ The group facilitator provides information about behavior modification techniques and helps to reinforce progress, but the onus of making behavior changes and the responsibility for success lies with the patient. Sessions focus more on reviewing patient progress and problem-solving related to barriers to change rather than on lecturing.

\section{Diet}

All patients are given a calorie reduction goal approximately equivalent to 500-1000 kcal less than their estimated daily maintenance energy requirements (a reduction of $25-50 \%$ in most individuals). Maintenance energy requirements can be estimated, in lieu of a direct determination of basal metabolic rate, by multiplying baseline body weight in pounds by 12 . Thus, for a $200 \mathrm{lb}$ individual, the daily maintenance caloric requirement would be $2400 \mathrm{kcal}$. In that 3500 calories is equivalent to 1 pound of body weight, subtracting 500-1000 calories/ day from estimated maintenance energy requirements would induce a 1-2 pound weight loss per week (approximately .5-1\% of body weight). Patients are generally encouraged to consume a complex-carbohydrate, lower-fat diet that emphasizes consumption of whole grains, fruits and vegetables in line with the Dietary Guidelines of the American Heart Association. ${ }^{45}$ While multiple dietary macronutrient approaches have been tested, ranging from high fat-low carbohydrate to low fat-high carbohydrate content, for weight loss to occur, the diet needs to 
be hypocaloric. For weight loss to be maintained, it needs to be compatible with long-term adherence and nutritionally sound. ${ }^{45}$ As a result, fad diets are discouraged.

\section{Exercise}

Physical activity alone is of limited benefit in inducing rapid weight loss over a 2-3 month time frame, however, it is a crucial component for longer-term weight loss (6-months and longer) and critical for long-term weight management. Recent evidence suggests that program participants who are prescribed higher levels of physical activity, ie, energy expenditure of 2500 kcals per week, maintain significantly greater weight losses at 12 and 18 months than participants with a standard activity goal of $1000 \mathrm{kcals} /$ week. ${ }^{17,46}$ The National Weight Control Registry was established in 1993 to examine the characteristics of individuals who are successful at long-term weight reduction examining individuals maintaining a $13.6 \mathrm{~kg}$ weight loss for $>1$ year. Physical activity habits of these successful individuals $(\mathrm{N}=3,683)$ was remarkable with participants reporting an average of 2,600 kcal/week of purposeful physical activity. ${ }^{47}$

\section{Outcomes of Behavioral Weight Loss}

Patients currently treated by a comprehensive outpatient behavioral approach to weight loss over a 4-6 month period lose approximately $8-12 \mathrm{~kg}$, equal to $11 \%$ of initial weight. ${ }^{48}$ In addition, approximately $80 \%$ of patients who begin a 4-6 month treatment, complete it. Therefore, lifestyle modification yields favorable results as judged by the criteria for success (a 5-10\% reduction in initial weight) proposed by the World Health Organization, the National Institutes of Health, and the Dietary Guidelines for Americans. ${ }^{49-51}$

\section{Design and Implementation of Weight Loss Programs in the CR Setting}

Most CR programs do not presently contain a formal, in-house weight management program. This needs to change. As an initial step towards the development of weight management programs, all CR programs should collect baseline and follow-up data of height, weight, BMI, and waist circumference as well as obesity related risk factors such as glucose level, lipid profile, and blood pressure. Additionally, programs need to implement continual quality improvement to improve weight loss outcomes in their Phase II CR patient population. While a framework for weight management in the CR setting is presented here, individual programs should develop clinically practical, culturally and regionally sensitive approaches to weight control with collection of short-, and longer-term outcomes that are effective and functional within the reimbursement system. CR programs have the option of linking with existing weight loss programs in their medical community, or establishing a weight loss program that can function within the confines of CR. We prefer the latter when possible. What is clear is that $C R / S e c o n d a r y$ Prevention Programs can no longer ignore the challenge of obesity management in patients with CHD. It is inadequate to merely point out to a patient that weight loss is indicated. We note that the weight reduction program we established in our CR program 10 years ago has enrolled over 500 individuals for medically indicated weight loss who were not otherwise participating in Phase II or Phase III CR. These patients all undergo a baseline medical evaluation, most require an exercise tolerance test, and many stay on long-term to participate in our Phase III CR exercise program to assist with weight loss maintenance.

\section{FUTURE RESEARCH}

Many questions remain as to how to best implement weight reduction in the CR setting:

1. What is the optimal time to implement weight loss in CR? We note that at CR entry, many patients are already overwhelmed with the preventive challenges ahead of them such as taking on an exercise program, new medications, adherence with smoking 
cessation, reducing dietary trans and saturated fats, returning to work, and family obligations.

2. If patients are willing to exercise but not willing to participate in behavioral weight loss, is there an optimal motivational process to move CR participants towards the "action phase' of behavioral weight loss to complement the exercise component?

3. How do we provide weight loss maintenance support after completion of Phase II CR as further weight reduction is medically indicated and processes for weight loss and weight loss maintenance are generally accomplished over a 6-12 month period?

4. Is there a role for resistance training in $\mathrm{CR}$ weight reduction programs to maintain muscle mass and preferentially promote fat mass loss $?^{27}$

5. Should the presence of a formal weight management process be considered as a requisite component in the American Associaiton of Cardiovascular and Pulmonary Rehabilitation CR program certification process?

6. Are there ways to individualize effective weight loss approaches based upon patient characteristics? A "one size fits all” approach will almost certainly not be effective for all patient personality types.

7. Finally, whether intentional weight reduction in the CR setting results in improved clinical outcomes in patients with CHD has not yet been clearly demonstrated. Multicenter randomized clinical trials of weight loss in CHD patients with assessment of long-term clinical outcomes need to be performed.

\section{Acknowledgments}

Supported by NIH grants RO1-HL72851 (P. Ades P.I.) and the General Clinical Research Center, University of Vermont (UVM) College of Medicine (RR-109).

\section{References}

1. Ogden CL, Carroll MD, Curtin LR, McDowell MA, Tabak CJ, Flegal KM. Prevalence of overweight and obesity in the United States, 1999-2004. JAMA 2006;295:1549-1555. [PubMed: 16595758]

2. Ades PA, Savage PD, Brawner CA, et al. Aerobic capacity in patients entering cardiac rehabilitation. Circulation 2006;113:2706-2712. [PubMed: 16754799]

3. Bader DS, Maguire TE, Spahn CM, O’Malley CJ, Balady GJ. Clinical profile and outcomes of obese patients in cardiac rehabilitation stratified according to National Heart, Lung, and Blood Institute criteria. J Cardiopulm Rehabil 2001;21:210-217. [PubMed: 11508180]

4. Audelin MC, Savage PD, Ades PA. Changing clinical profile of patients entering cardiac rehabilitation/ secondary prevention programs: 1996 to 2006. J Cardiopulm Rehabil Prev 2008;28:299-306. [PubMed: 18784538]

5. Ross R, Dagnone D, Jones PJ, et al. Reduction in obesity and related comorbid conditions after dietinduced weight loss or exercise-induced weight loss in men. A randomized, controlled trial. Ann Intern Med 2000;133:92-103. [PubMed: 10896648]

6. Reaven GM. Banting lecture 1988. Role of insulin resistance in human disease. Diabetes 1988;37:1595-1607. [PubMed: 3056758]

7. Grundy SM, Cleeman JI, Daniels SR, et al. American Heart Association; National Heart, Lung, and Blood Institute. Diagnosis and management of the metabolic syndrome: an American Heart Association/National Heart, Lung, and Blood Institute Scientific Statement. Circulation 2005;112:2735-2752. [PubMed: 16157765]

8. Alberti KGMM, Eckel RH, Grundy SM, et al. Harmonizing the metabolic syndrome: A joint interim statement of the International Diabetes Federation Task Force on Epidemiology and Prevention; National Heart, Lung, and Blood Institute; American Heart Association; World Heart Federation; 
International Atherosclerosis Society; and International Association for the Study of Obesity. Circulation 2009;120:1640-1645. [PubMed: 19805654]

9. Rana JS, Mukamal KJ, Morgan JP, Muller JE, Mittleman MA. Obesity and the risk of death after acute myocardial infarction. Am Heart J 2004;147:841-846. [PubMed: 15131540]

10. Wolk R, Berger P, Lennon RJ, Brilakis ES, Somers VK. Body mass index: a risk factor for unstable angina and myocardial infarction in patients with angiographically confirmed coronary artery disease. Circulation 2003;108:2206-2211. [PubMed: 14557360]

11. Wilson PW, D’Agostino RB, Sullivan L, Parise H, Kannel WB. Overweight and obesity as determinants of cardiovascular risk: the Framingham experience. Arch Intern Med 2002;162:186772. [PubMed: 12196085]

12. Schwartz GG, Olsson AG, Szarek M, Sasiela WJ. Relation of characteristics of metabolic syndrome to short-term prognosis and effects of intensive statin therapy after acute coronary syndrome: an analysis of the Myocardial Ischemia Reduction with Aggressive Cholesterol Lowering (MIRACL) trial. Diabetes Care 2005;28:2508-1253. [PubMed: 16186288]

13. Levantesi G, Macchia A, Marfisi R, et al. GISSI-Prevenzione Investigators. Metabolic syndrome and risk of cardiovascular events after myocardial infarction. J Am Coll Cardiol 2005;46:277-283. [PubMed: 16022955]

14. Daly CA, Hildebrandt P, Bertrand M, et al. EUROPA investigators. Adverse prognosis associated with the metabolic syndrome in established coronary artery disease: data from the EUROPA trial. Heart 2007;93:1406-11. [PubMed: 17540689]

15. Milani RV, Lavie CJ. Prevalence and profile of metabolic syndrome in patients following acute coronary events and effects of therapeutic lifestyle change with cardiac rehabilitation. Am J Cardiol 2003;92:50-54. [PubMed: 12842245]

16. Lavie CJ, Milani RV. Cardiac rehabilitation and exercise training programs in metabolic syndrome and diabetes. J Cardiopulm Rehabil 2005;25:59-66. [PubMed: 15818190]

17. Ades PA, Savage PD, Toth MJ, et al. High-caloric expenditure exercise: A new approach to cardiac rehabilitation for overweight coronary patients. Circulation 2009;119:2671-2678. [PubMed: 19433757]

18. Knowler WC, Barrett-Connor E, Fowler SE, et al. Reduction in the incidence of type 2 diabetes with lifestyle intervention or metformin. N Engl J Med 2002;346:393-403. [PubMed: 11832527]

19. Aguilar D, Solomon SD, Kober L, et al. Newly diagnosed and previously known diabetes mellitus and 1-year outcomes of acute myocardial infarction: the VALsartan In Acute myocardial iNfarcTion (VALIANT) trial. Circulation 2004;110:1572-1578. [PubMed: 15364810]

20. Vaccarino V, Parsons L, Every NR, Barron HV, Krumholz HM. Impact of history of diabetes mellitus on hospital mortality in men and women with first acute myocardial infarction. The National Registry of Myocardial Infarction 2 Participants. Am J Cardiol 2000;85:1486-1489. A1487. [PubMed: 10856398]

21. Berger AK, Breall JA, Gersh BJ, et al. Effect of diabetes mellitus and insulin use on survival after acute myocardial infarction in the elderly (the Cooperative Cardiovascular Project). Am J Cardiol 2001;87:272-277. [PubMed: 11165959]

22. Mukamal KJ, Nesto RW, Cohen MC, et al. Impact of diabetes on long-term survival after acute myocardial infarction: comparability of risk with prior myocardial infarction. Diabetes Care 2001;24:1422-1427. [PubMed: 11473080]

23. Eilat-Adat S, Eilat-Adar S, Eldar M, Goldbourt U. Association of intentional changes in body weight with coronary heart disease event rates in overweight subjects who have an additional coronary risk factor. Am J Epidemiol 2005;161:352-358. [PubMed: 15692079]

24. Sierra-Johnson J, Romero-Corral A, Somers VK, et al. Prognostic importance of weight loss in patients with coronary heart disease regardless of initial body mass index. Eur J Cardiovasc Prev Rehabil 2008;15:336-340. [PubMed: 18525390]

25. Brochu M, Poehlman ET, Savage P, Fragnoli-Munn, Ross S, Ades PA. Modest effects of exercise training alone on coronary risk factors and body composition in coronary patients. J Cardiopulm Rehabil 2000;20:180-188. [PubMed: 10860200]

26. Lamonte MJ, Ainsworth BE. Quantifying energy expenditure and physical activity in the context of dose response. Med Sci Sports Exerc 2001;33(6 Suppl):S370-S378. Review. [PubMed: 11427762] 
27. Hunter GR, Byrne NM, Sirikul B, et al. Resistance training conserves fat-free mass and resting energy expenditure following weight loss. Obesity (Silver Spring) 2008;16:1045-1051. [PubMed: 18356845]

28. Hancock K, Davidson PM, Daly J, Webber D, Chang E. An exploration of the usefulness of motivational interviewing in facilitating secondary prevention gains in cardiac rehabilitation. $\mathbf{J}$ Cardiopulm Rehabil 2005;25:200-206. [PubMed: 16056065]

29. Mertens DJ, Kavanagh T, Campbell RB, Shephard RJ. Exercise without dietary restriction as a means to long-term fat loss in the obese cardiac patient. J Sports Med Phys Fitness 1998;38:310-316. [PubMed: 9973774]

30. Savage PD, Brochu M, Scott P, Ades PA. Low caloric expenditure in cardiac rehabilitation. Am Heart J 2000;140:527-533. [PubMed: 10966557]

31. Schairer JR, Kostelnik T, Proffitt SM, et al. Caloric expenditure during cardiac rehabilitation. J Cardiopulm Rehabil 1998;18:290-294. [PubMed: 9702608]

32. Zeni AI, Hoffman MD, Clifford PS. Energy expenditure with indoor exercise machines. JAMA 1996;275:1424-1427. [PubMed: 8618368]

33. DeFronzo R, Tobin J, Andres R. Glucose clamp technique: a method for quantifying insulin secretion and resistance. Am J Physiol 1979;237:E214-E233. [PubMed: 382871]

34. Savage PD, Ludlow M, Toth MJ, et al. Exercise and weight loss improves endothelial dependant vasodilatory capacity in overweight individuals with coronary heart disease (Abstr). J Cardiopulm Rehabil Prev 2009;29:264.

35. Keating FK, Schneider DJ, Savage PD, Bunn JY, Toth MJ, Ades PA. Platelet reactivity decreases after exercise training and weight loss in overweight patients with coronary artery disease. (Abstr) Circulation. 2009

36. Savage PD, Brochu M, Poehlman ET, Ades PA. Reduction in obesity and coronary risk factors after high caloric exercise training in overweight coronary patients. Am Heart J 2003;146:317-323. [PubMed: 12891202]

37. Swain DP, Franklin BA. Is there a threshold intensity for aerobic training in cardiac patients? Med Sci Sports Exerc 2002;34:1071-1075. [PubMed: 12131243]

38. Hamm LF, Kavanagh T, Campbell RB, et al. Timeline for peak improvements during 52 weeks of outpatient cardiac rehabilitation. J Cardiopulm Rehabil 2004;24:374-380. [PubMed: 15632770]

39. Carlson JJ, Johnson JA, Franklin BA, VanderLaan RL. Program participation, exercise adherence, cardiovascular outcomes, and program cost of traditional versus modified cardiac rehabilitation. Am J Cardiol 2000;86:17-23. [PubMed: 10867086]

40. Hambrecht R, Niebauer J, Marburger C, et al. Various intensities of leisure time physical activity in patients with coronary artery disease: effects on cardiorespiratory fitness and progression of coronary atherosclerotic lesions. J Am Coll Cardiol 1993;22:468-477. [PubMed: 8335816]

41. Brownell, K. The LEARN program for weight control. American Health Publishing Co; Dallas, TX: 2000.

42. Harvey-Berino J. Weight loss in the clinical setting: applications for cardiac rehabilitation. Coronary Artery Disease 1998;9:795-798. [PubMed: 9894923]

43. Harvey-Berino, J.; Hendley, J. the Editors of Eating Well. The EatingWell Diet. The Countryman Press; Woodstock, VT: 2007.

44. Ades, PA. the Editors of Eating Well. EatingWell for a Healthy Heart Cookbook. The Countryman Press; Woodstock, VT: 2008.

45. Lichtenstein AH, Appel LJ, Brands M, et al. Summary of American Heart Association diet and lifestyle recommendations revision, 2006. Arterioscler Thromb Vasc Biol 2006;26:2186-2191. [PubMed: 16990564]

46. Jeffery RW, Wing RR, Sherwood E, Tate DF. Physical activity and weight loss: Does prescribing higher physical activity goals improve outcome? Am J Clin Nutr 2003;78:684-689. [PubMed: 14522725]

47. Catenacci VA, Ogden LG, Stuht J, et al. Physical activity patterns in the National Weight Control Registry. Obesity (Silver Spring) 2008;16:153-161. [PubMed: 18223628]

48. Wadden TA, Butryn ML, Wilson C. Lifestyle modification for the management of obesity. Gastroenterol 2007;132:2226-2238. 
49. World Health Organization. WHO Technical Report Series No. 894. Geneva, Switzerland: WHO; 2000. Obesity: Preventing and Managing the Global Epidemic. Report of a WHO Consultation.

50. National Institutes of Health. The Practical Guide: Identification, Evaluation, and Treatment of Overweight and Obesity in Adults. Bethesda, MD: National Institutes of Health; 2000.

51. US Department of Agriculture. Home and Garden Bulletin No 232. U.S. Government Printing Office; Washington, DC: 2000. Nutrition and Your Health: Dietary Guidelines for Americans. 


\section{The Energy Balance Equation}

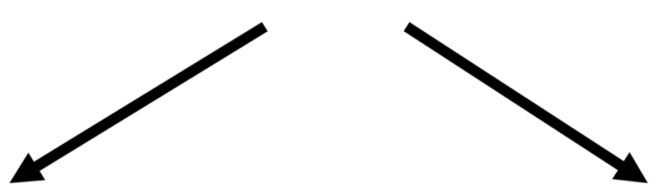

\begin{tabular}{|c|}
\hline Energy Intake \\
Caloric Consumption
\end{tabular}

\section{Energy Expenditure}

(1) Resting Metabolic Rate

(2) Thermal Effect of Food

(3) Physical Activity Energy Expenditure

Figure 1.

The Energy Balance Equation. In a steady state situation, energy intake would equal energy expenditure. 


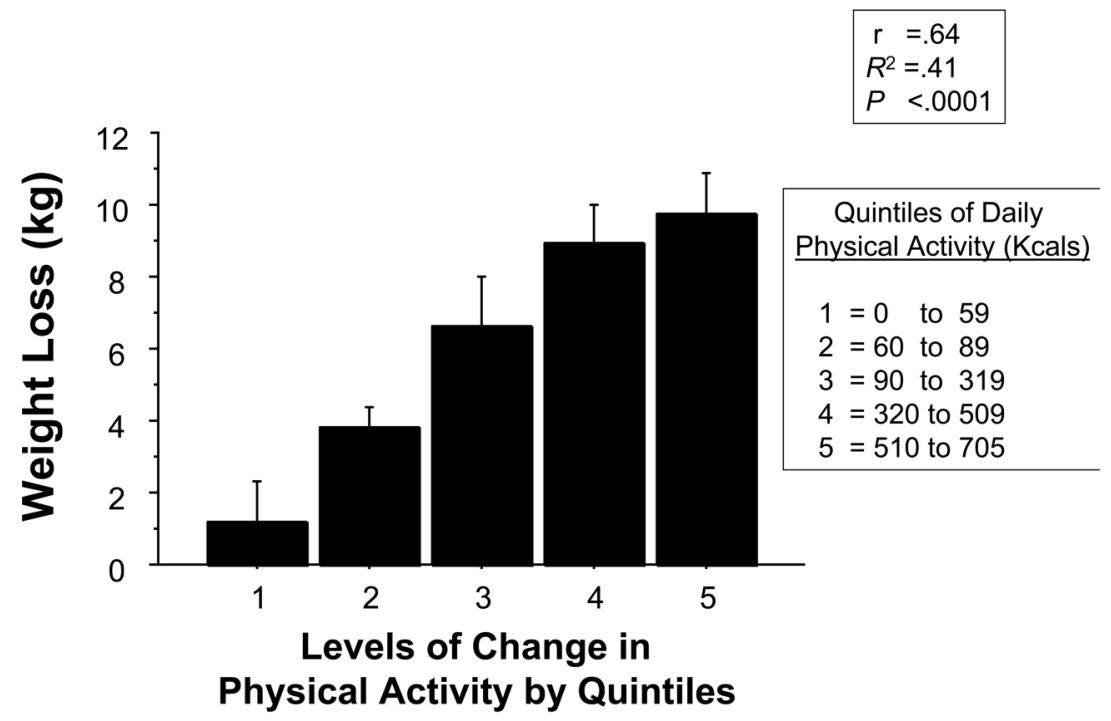

Figure 2.

Quintiles of Physical Activity by Accelerometer (Kcal/day) vs. Weight Loss ( $\mathrm{r}=0.64, P<$. 0001). ${ }^{17}$ 


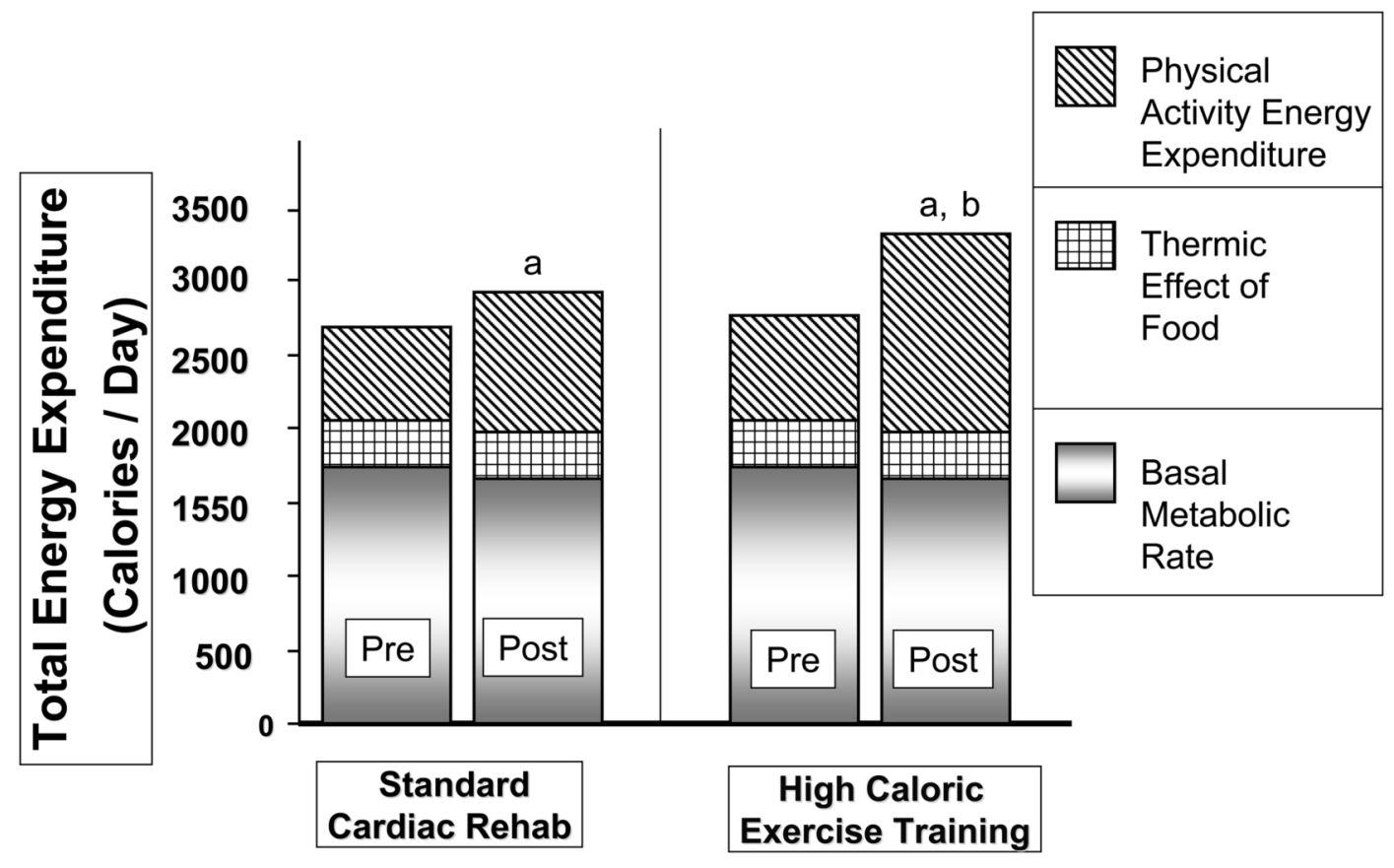

Figure 3.

Components of total daily energy expenditure by group, before and after weight loss and exercise. ${ }^{17}$ a $P<.05$ within group for physical activity energy expenditure. ${ }^{b} P<.05$ change prepost between groups for physical activity energy expenditure. 


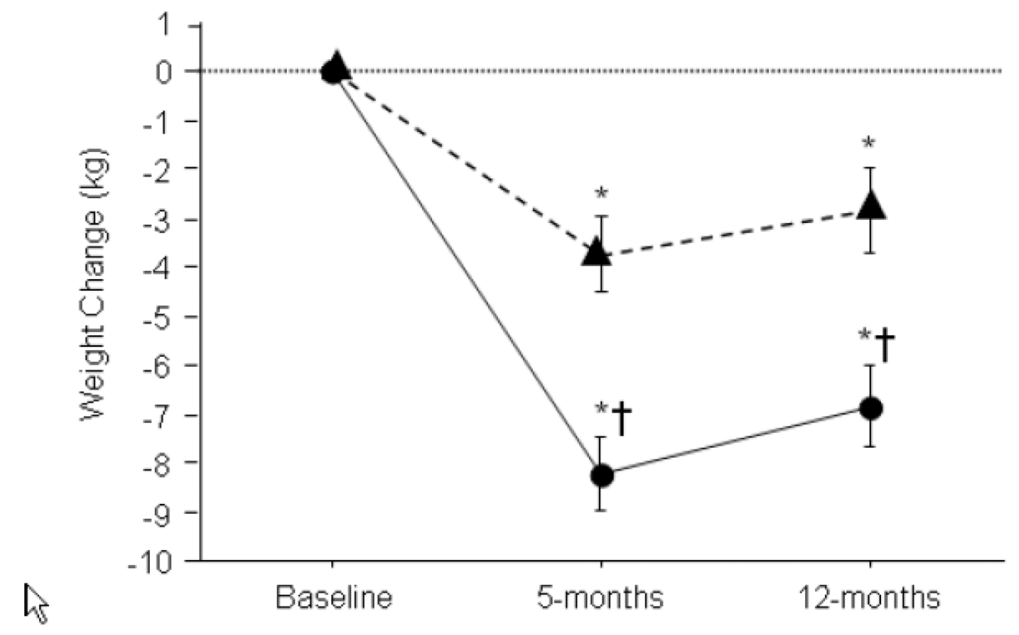

Figure 4.

Weight loss by group at 5 and 12 months (with permission, American Heart Association). ${ }^{17}$ $* P<.05$ vs. baseline. $\dagger P<.05$ vs. change in standard cardiac rehabilitation group. 


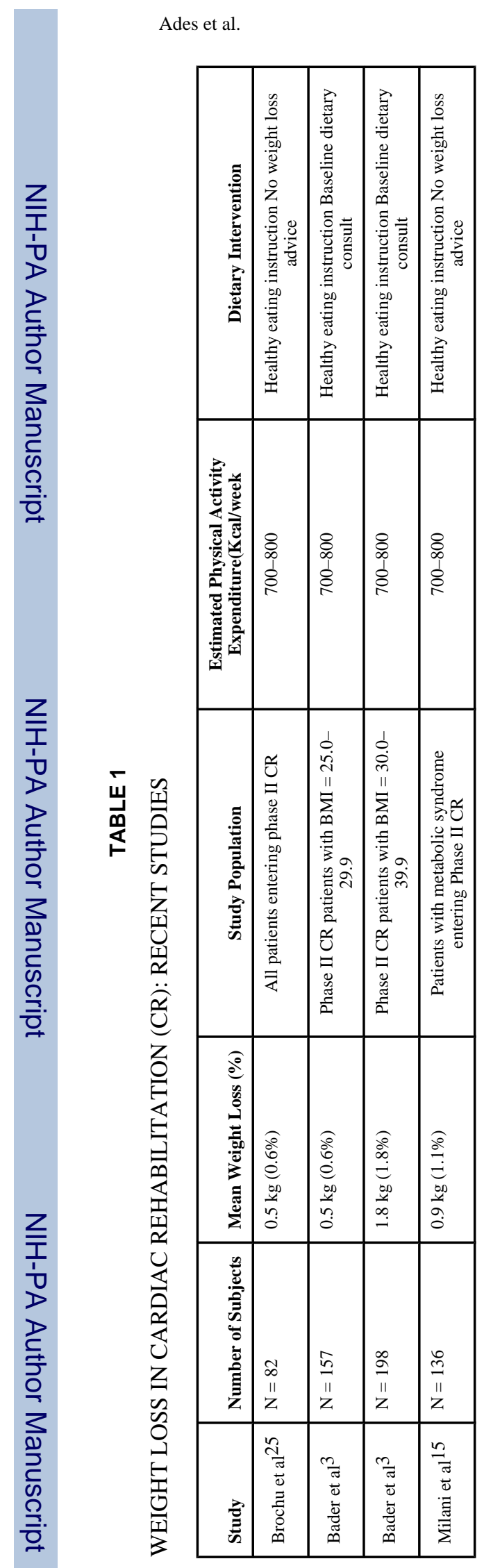

Page 16 


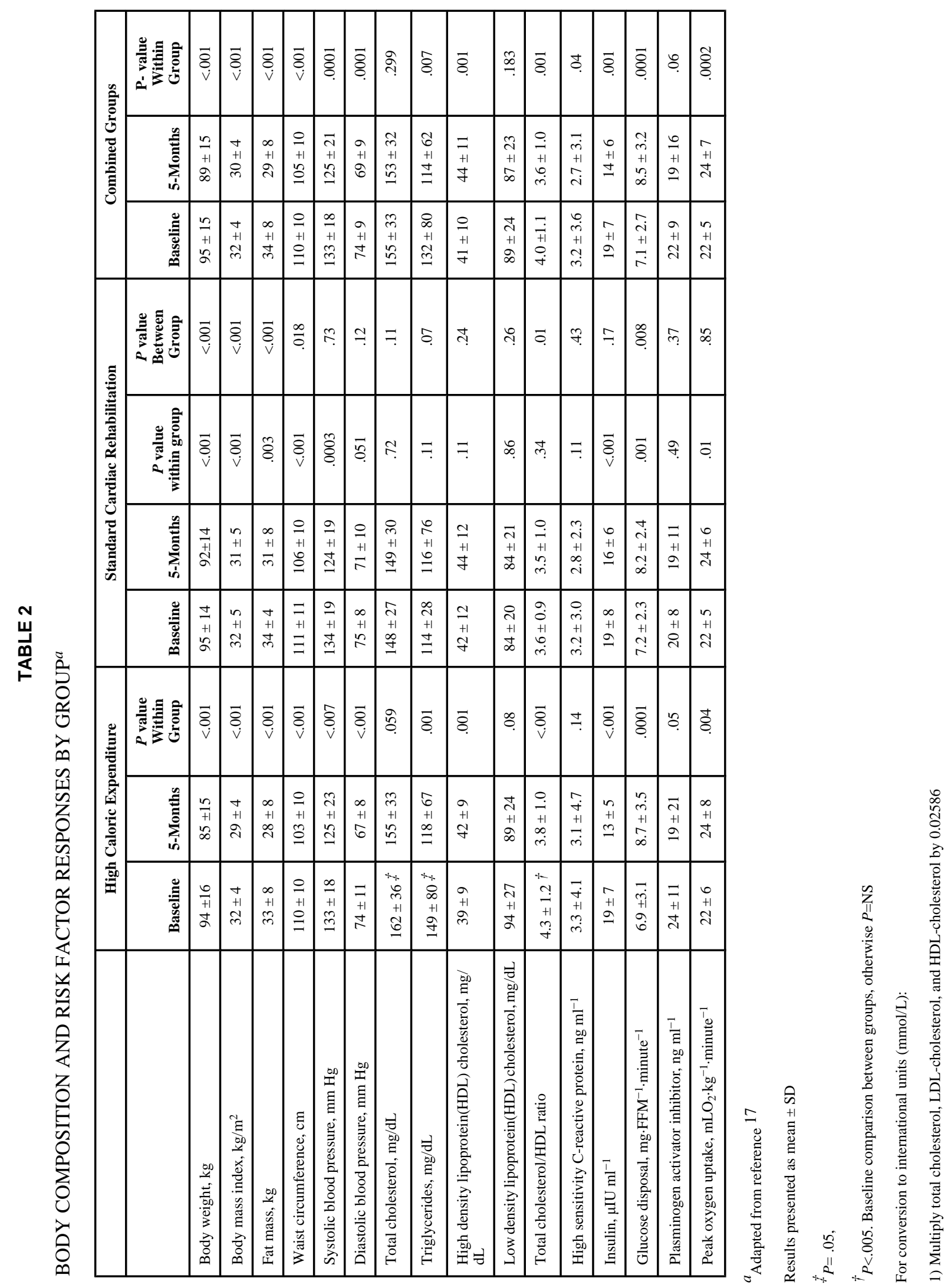




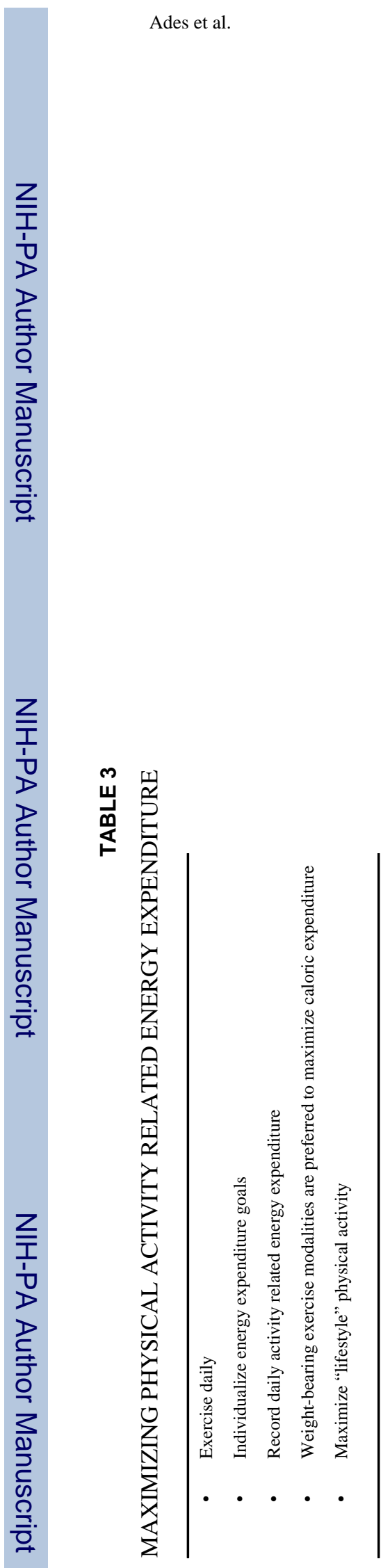

J Cardiopulm Rehabil Prev. Author manuscript; available in PMC 2011 September 1. 
